\section{Dependence of Insulin Haemagglutination Antibody Titres on IgM Antibody}

SINCE Moinat's ${ }^{1}$ investigations of haemagglutination antibody titres to insulin, it has been assumed that there is no relationship between insulin requirements and antibody titres except in some cases of insulin resistance. These observations were partly supported by Berson and Yalow ${ }^{2}$, although these authors did find insulin binding capacities ranging from 50 to 500 units/litre in insulin-resistant patients. Recent investigations in this laboratory ${ }^{3}$ on variations in insulin requirements in human subjects with differing species of insulin suggested that antibodies to insulin play a significant role in determining insulin requirements even in non-resistant subjects. It was important, therefore, to re-investigate the haemagglutination studies in order to determino whether they reflected a true picture of insulin antibody titres or whether they might be IgM antibody dependent $t^{4,5}$. have not always proved satisfactory because of limited resolution and because of interaction with the specimen. In the course of studying the site of aldehydic groups in tropocollagen we developed a new method of negative staining. This gives delicate outlines of good contrast with macromolecular aggregates that are difficult to visualize with other techniques.

Ichthyocol tropocollagen was prepared as described by Gallop ${ }^{3}$ and kept in the cold until required. Fifty milligrams of dry protein was dissolved in $50 \mathrm{ml}$. of cold $0.05 \mathrm{M}$ acetic acid and centrifuged at $100,000 \mathrm{~g}$ to remove the undissolved particles. The native fibrils were reconstituted by dialysis of the ichthyocol solution against $0.02 \mathrm{M}$ sodium phosphate. When the fibrils started to precipitate, a drop was applied on a film of nitrocellulose reinforced with carbon supported on 300 mesh copper grids. After 30 sec the drop was rapidly removed by touching one edge with a piece of filter paper. After a brief period of air drying the grids were placed about

\begin{tabular}{lcc} 
Case & \multicolumn{2}{c}{$\begin{array}{c}\text { Haemagglutination titres } \\
\text { 2-Mercapto-ethanol } \\
\text { treated }\end{array}$} \\
K.F. & $1 / 40$ & $1 / 5$ \\
M.H. & $1 / 20$ & $1 / 5$ \\
J.C. & $1 / 40$ & $1 / 5$ \\
T.S. & $1 / 20$ & $1 / 5$ \\
A.S. & $1 / 80$ & $1 / 5$ \\
W.R. & $1 / 80$ & $1 / 5$ \\
D.P. & $1 / 80$ & $1 / 20$ \\
A.D. & $1 / 20$ & $-\mathrm{ve}$ \\
C.G. & $1 / 40$ & $-\mathrm{ve}$ \\
M.H. & $1 / 160$ & $1 / 20$ \\
O.B. & $1 / 10$ & $1 / 160$ \\
C.M. & $1 / 160$ & $1 / 40$ \\
* Not calculated. & &
\end{tabular}

Sera from twelve insulin-treated diabetic patients were investigated. $0.5 \mathrm{ml}$. of the serum was incubated with $0.1 \mathrm{ml}$. of $0.4 \mathrm{M} 2$-mercapto-ethanol for $24 \mathrm{~h}$ at $4^{\circ} \mathrm{C}$. The mercapto-ethanol was removed by desalting on a 'Sephadex $G$ 25' column, volume $1.4 \mathrm{ml}$., equilibrated with $0.06 \mathrm{M}$ phosphate buffer, $p \mathrm{H} 7 \cdot 2$, and the following analyses were carried out on the eluates: haemagglutination titres, IgG and IgM antibody levels ('Immuno-Plate', Hyland Laboratories) and determination of the percentage binding of $0.1 \mathrm{~m} \mu \mathrm{g}{ }^{125} \mathrm{I}$-insulin (Amersham). Duplicate investigations of all sera using buffer instead of 2 -mercapto-ethanol were carried out. The results are shown in Table 1. In all except one of the sera tested there was a marked fall in haemagglutination titre; this was accompanied by a drop in IgM antibody levels in all cases, while IgG antibody levels and ${ }^{125} \mathrm{I}$-insulin binding remained unaltered. It is therefore concluded that insulin haemagglutination antibody titres do not give a true picture of insulin antibody levels but are mainly dependent on the titre of insulin binding IgM antibody.

\section{James G. Devlin}

Department of Medicine,

MARK LAHER

University College,

Dublin.

' Moinat, P., Diabetes, 7, 462 (1958).

"Berson, S. A., and Yalow, R. S., J. Clin. Invest., 38, 1996 (1959).

${ }^{3}$ Devlin, J. G., and Brien, T. G., Metabolism, 14, 1034 (1964).

4 Benedict, A. A., Nature, 206, 1368 (1965).

' Onoue, K., Tonigaki, N., Yagi, Y., and Pressman, D., Proc. Soc. Exp. Biol. noue, K., Tonigaki, Ned, 120,340 (1965).
and

\section{HISTOLOGY}

\section{Negative Staining with Osmium Tetroxide Vapour}

Negative staining has become widely accepted as a means of visualizing macromolecular structures under the electron microscope $e^{1,2}$. Its advantages lie in its simplicity and the high contrast which it offers. Many of the heavy metal salts used as negative stains, however,
Table 1

$\begin{array}{cccc}\begin{array}{c}\text { eduction of } \\ \text { IgM level } \\ \text { (per cent) }\end{array} & \begin{array}{c}\text { Reduction of } \\ \text { IgG level } \\ \text { (per cent) }\end{array} & \begin{array}{c}{ }^{125} \text { I-Insulin binding (per cent) } \\ \text { Buffer treated }\end{array} & \begin{array}{c}\text { 2-Mercapto-ethanol } \\ \text { treated }\end{array} \\ 68 \cdot 0 & \text { nil } & 65 \cdot 9 & 63 \cdot 6 \\ 84 \cdot 5 & \text { nil } & 69 \cdot 1 & 75 \\ 93 \cdot 0 & 0 \cdot 9 & 67 & 55 \\ 74 \cdot 2 & 5 \cdot 3 & 58 & 83 \\ 63 \cdot 6 & \text { nil } & 87 & 63 \\ 40 \cdot 8 & \text { nil } & 68 & 67 \\ 54 \cdot 4 & \text { nil } & 53 \cdot 2 & 53 \\ 47 \cdot 1 & 15 \cdot 4 & 41 & 40 \\ 52 \cdot 3 & 5 & 32 \cdot 3 & 72 \\ * & * & 82 & 60 \\ 78 \cdot 2 & * & 77 & \\ * & * & 56 & \end{array}$

$5 \mathrm{~cm}$ above a beaker containing a 2 per cent solution of osmium tetroxide and maintained at room temperature for varying periods of time. The individual grids were examined in an electron microscope using a $60 \mathrm{kV}$ beam and a $50 \mathrm{~m} \mu$ objective aperture.

Segmental long spacing (SLS) fragments of collagen were obtained after addition of $\operatorname{ATP}$ (acid form) to the

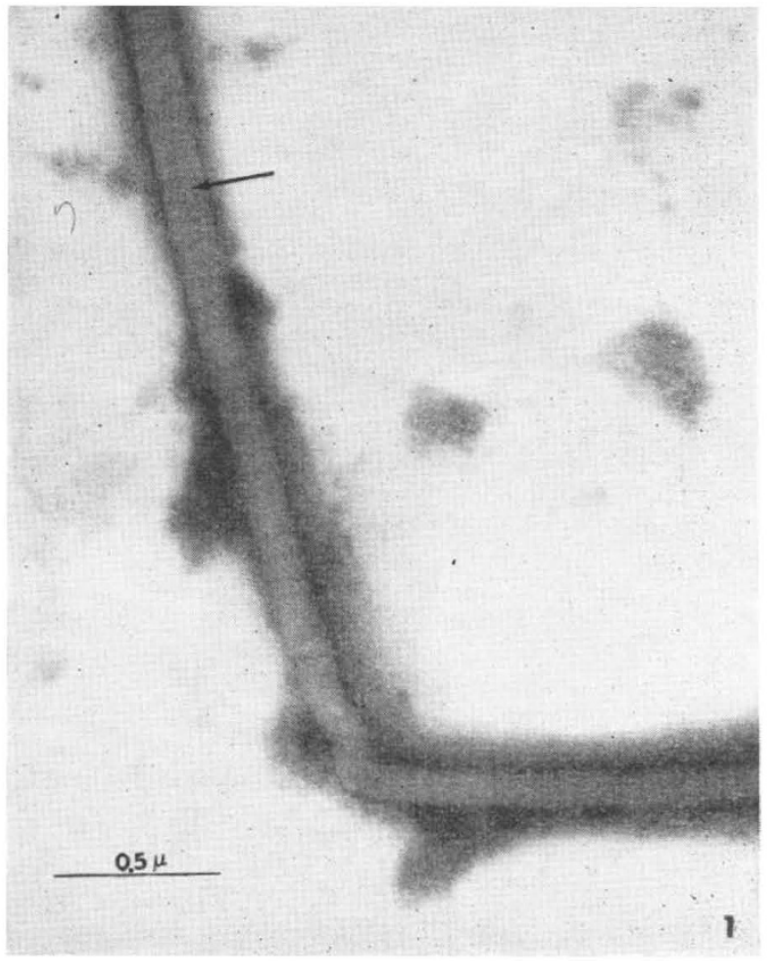

Fig. 1. A native collagen fibre exposed to osmium tetroxide vapour for $30 \mathrm{~min}$. The fibres were mounted on the grid from a suspension in pure
water. Both longitudinal (arrow) and cross striations are discernible. $(\times 16,500$. 